\title{
The Effect of Serum on the PEG-Based Crosslinker-Induced Spheroid Formation of Pancreatic $\beta$-Cell
}

\author{
Michiko Ito and Tetsushi Taguchi*
}

Biomaterials Center, National Institute for Materials Science, 1-1, Namiki, Tsukuba, Ibaraki, 305-0044, Japan

\begin{abstract}
A polymeric crosslinker poly(ethylene glycol) derivative with dioleyl groups as hydrophobic group at both ends was developed for promoting cellular spheroid formation. Our approach to bridge cells was based on the crosslinking of cell membrane using a crosslinker via the hydrophobic interaction. Using the crosslinker, spheroid formation of pancreatic $\beta$-cell line RIN in a round bottom 96-well plate was evaluated, especially in effect of serum on spheroid formation. In the presence or absence of serum, the size of prepared spheroid was found to decrease with increasing culture time and with increasing crosslinker concentration. However, the medium without serum proved to be a favorable condition for promoting cell aggregation because in this case spheroid with smaller size could be obtained. It was clarified that spheroid formation and insulin secretion of the spheroid prepared by the crosslinker were enhanced, especially in the medium without serum.
\end{abstract}

\section{INTRODUCTION}

Tissue engineering is an emerging technology that can be used to repair and regenerate damaged human tissue [1-3]. The technique of tissue engineering has taken a lead role in producing new tissue using materials and cells. Cells are commonly cultured in vitro as monolayers in plastic flasks. However, it is well-known that there is a significant difference between cells lying within flat layer (2D culture) and cells embedded in three-dimensional tissue (3D culture) [48]. $2 \mathrm{D}$ culture has a drawback of destroying the characteristic cell arrangement, thus, interrupting normal inter-cell regulatory mechanisms. On the other hand, the function of cells in 3D culture generally escalates because of the enhanced cell-cell interaction. Therefore, researches on the formation and use of cell spheroid (multicellular mass) have drawn considerable interests. The cells in a spheroid are known to possess enhanced functions as compared to those in case of isolated cells; therefore, spheroid has great potential for its application in the field of tissue engineering.

Recently, we have developed a polymeric crosslinker which can enhance the formation of spheroid. Our approach is based on bridging cell membrane composed of phospholipid using a polymeric crosslinker via hydrophobic interaction. Using hydrophobic interaction, we believe that cell membrane of different cells can be anchored without causing any damage to the structure. The hydrophobic unit such as lipid, e.g., cholesterol and oleyl chain can anchor to phospholipids bilayer of lipid membranes such as liposomes and cells [9-18]. The designed polymeric crosslinker consists of two distinct units: Hydrophobic unit which can anchor to phospholipids bilayer of cell membrane, and a hydrophilic unit which promotes water solubility to utilize in aqueous media. We hypothesized that when this kind of polymeric crosslinker is added to cell suspensions, physical crosslink-

*Address correspondence to this author at the Biomaterials Center, National Institute for Materials Science, 1-1, Namiki, Tsukuba, Ibaraki, 305-0044, Japan; E-mail: TAGUCHI.Tetsushi@nims.go.jp ing will occur among cells via hydrophobic interaction. We recently synthesized a crosslinker that employed oleyl group as hydrophobic unit and poly(ethylene glycol) (PEG) chain as hydrophilic unit [19]. In the present study, the effect of serum on the PEG-based crosslinker-induced spheroid formation was investigated; also, the biological function of resulting spheroids was evaluated using rat pancreatic $\beta$-cell line RIN.

\section{EXPERIMENTAL}

\section{Materials}

Oleyl-O-poly(ethylene glycol)-succinyl $N$-hydroxy-succinimidyl ester (SUNBRIGHT ${ }^{\circledR}$ OE-080CS, MW = 8,525) was obtained from NOF Corporation (Tokyo, Japan). Other chemicals were purchased from Wako Pure Chemical Industries, Ltd. (Osaka, Japan) and were used without further purification.

\section{Synthesis of Crosslinker}

A mixture of oleyl- $O$-poly(ethylene glycol)-succinyl $\mathrm{N}$ hydroxy-succinimidyl ester $(561 \mathrm{mg}, 66 \mu \mathrm{mol})$ and ethylenediamine $(2 \mu \mathrm{L}, 30 \mu \mathrm{mol})$ in $N, N^{\prime}$-dimethylformamide (DMF) (4 mL) was kept stirred at room temperature for an overnight. The solvent was then removed by evaporation under a reduced pressure and then the residue was purified via dialysis against water. The resulting solution was lyophilized by freeze-drying to produce a crosslinker $(535 \mathrm{mg}$, $79 \%$ purity by GPC, $84 \%$ yield) in form of a white fluffy material. The product was characterized with gel permeation chromatography (GPC) (HLC-8220GPC system equipped with RI, TSKgel G4000H $\mathrm{H}_{\mathrm{HR}}$ and TSKgel G3000H $\mathrm{HR}_{\mathrm{HR}}$ columns, Tosoh Corporation, Tokyo, Japan) in DMF (with 10 $\mathrm{mM} \mathrm{LiCl}$ additive) and with Fourier-transform infrared spectroscopy (FT-IR) (FTIR-8400S, Shimadzu Corporation, Kyoto, Japan). GPC: $\mathrm{M}_{\mathrm{n}}=17585, \mathrm{M}_{\mathrm{w}}=18042$. IR $\left(\mathrm{KBr}, \mathrm{cm}^{-}\right.$ $\left.{ }^{1}\right)$ : $2889(\mathrm{C}-\mathrm{H}$ of alkane $), 1736(\mathrm{C}=\mathrm{O}$ of ester $), 1655(\mathrm{C}=\mathrm{O}$ of amide), $1543\left(\mathrm{~N}-\mathrm{H}\right.$ of amide), $1470\left(\mathrm{C}-\mathrm{H}\right.$ of $\left.-\mathrm{CH}_{2} \mathrm{O}-\right)$, 
1342 (C-H of alkane), 1281 (C-H of alkane), 1095 (C-C of alkane, $\mathrm{C}-\mathrm{O}$ of ether).

\section{Cell Culture}

A rat pancreatic $\beta$-cell line RIN grown in a RPMI-1640 medium (Sigma, MO, USA) containing $2 \%$ penicillinstreptomycin (Invitrogen Corporation, CA, USA) and 10\% fetal bovine serum (FBS) (Invitrogen Corporation, CA, USA) was used for the experiment. Cells $\left(1 \times 10^{5}\right.$ cells/well $)$ were seeded on a 96-well spheroid-plate with a non-adhesive surface and round bottom (Sumilon celltight ${ }^{\circledR}$ spheroid $96 \mathrm{U}$ plate, Sumitomo Bakelite co., Ltd., Tokyo, Japan) in 100 $\mu \mathrm{L} /$ well culture medium with or without FBS supplemented. Then, the crosslinker sterilized under UV for $15 \mathrm{~min}(0$, $0.25,2.5$ or $25 \mathrm{mg} / \mathrm{mL}$ ) in PBS was added with $100 \mu \mathrm{L}$ portion per well. They were cultured in a humidified incubator (ESPEC Corp., Osaka, Japan) at $37{ }^{\circ} \mathrm{C}$ in $5 \% \mathrm{CO}_{2}$ ambient. After every 3 days, half of the culture medium was replenished with new medium. Cell growth was recorded using an optical microscope (Olympus Corporation, Tokyo, Japan) with $4 \times$ objective lenses and a camera.

\section{Biochemical Characterization}

In order to assess the function of these spheroids, insulin secretion and DNA content were measured. The existing medium was removed, and RPMI-1640 medium containing 2 $\mathrm{g} / \mathrm{L}(11 \mathrm{mM})$ glucose without FBS was added. After incubation at $37{ }^{\circ} \mathrm{C}$ in $5 \% \mathrm{CO}_{2}$ for $1 \mathrm{~h}$, the samples were centrifuged, and the supernatant was preserved at $-80{ }^{\circ} \mathrm{C}$ until insulin measurement. After the remaining medium was removed the sample was lyophilized and stored in a desiccator until DNA determination. Insulin secretion by the pancreatic $\beta$-cell spheroid was determined by a sandwich enzymelinked immunosorbent assay (ELISA) kit (Shibayagi Co., Ltd., Gunma, Japan) for rat insulin according to the manufacturer's instructions. In order to determine DNA content the cells were digested in $150 \mu \mathrm{L}$ of papain PBS solution $\left(125 \mathrm{mg} / \mathrm{mL}, 5 \mathrm{mM}\right.$ L-cysteine, $5 \mathrm{mM}$ EDTA) at $60{ }^{\circ} \mathrm{C}$ for $24 \mathrm{~h}$. DNA content was then analyzed using Hoechst 33258 [20].

\section{Statistical Analysis}

Statistical analysis was carried out using Microsoft Excel's statistical function for Student's $t$-test. Statistical significant difference was considered when $p<0.01$ versus crosslinker (-). The data were represented as mean \pm standard deviation (S.D.).

\section{RESULTS}

\section{Cell Culture with Crosslinker}

The polymeric crosslinker was prepared using a coupling reaction between ethylenediamine and oleyl- $O$-PEG possessing amino-reactive $N$-hydroxysuccinimide (NHS) in DMF at room temperature. Using the obtained crosslinker, cell culture experiments were performed to confirm the formation of spheroid. Especially, the effects of serum and crosslinker concentration on the spheroid formation were evaluated. A round bottom 96-well spheroid-plate ${ }^{\circledR}$ was employed as a vessel to make the task easier to evaluate. Because of the shape of the vessel, the cells spontaneously gather in the bottom, and form into a single cell mass in each well. The rat pancreatic $\beta$-cell line RIN possessing ability of insulin secretion was used. Fig. (1) shows the results of microscopic observations after the addition of crosslinker at various concentrations to cell. Fig. (1A-H) show the formation of spheroid cultured in serum free medium, while Fig. (1I-P) show the formation of spheroid cultured in serum-containing medium. The spheroid formation was promoted in the presence of the crosslinker. The size of spheroid gradually decreased with time at any crosslinker concentration. After 3 days, the difference in the spheroid size was noted. The size of spheroids slightly decreased with increasing crosslinker concentration, regardless of the existence of the serum supplementation. In the absence of serum, the size of the spheroid that used 0.25 $\mathrm{mg} / \mathrm{mL}$ crosslinker (Fig. 1B) was found to be small as compared to the size of the spheroid without crosslinker (Fig. 1A). In other words, cell aggregation effect existed even at low crosslinker concentration in the absence of serum. On the other hand, cell aggregation effect was not observed at low crosslinker concentration $(0.25 \mathrm{mg} / \mathrm{mL})$ in the presence of serum (compared Fig. 1I and 1J). Compared with same crosslinker concentration, the size of spheroid cultured without serum was found to be smaller than that without serum. These results suggested that serum affected the cell aggregation.

\section{Determination of Cell Number}

After different culture periods, spheroids were digested by papain to determine DNA content. The number of cells was estimated from the amount of DNA. The number of cells in spheroids cultured after 7 days with different crosslinker concentrations was determined (Fig. 2). In serum free condition, the number of cells cultured with crosslinker significantly decreased for 7 days, whereas the number of cells did not change when cultured without crosslinker. The number of cells cultured without crosslinker remained nearly constant during the 7 days, and which hardly had proliferated (data not shown). On the other hand, the number of cells did not change when the crosslinker concentration was varied from 0 to $2.5 \mathrm{mg} / \mathrm{mL}$ in serum-containing medium. The number of cells remarkably decreased at the condition of 25 $\mathrm{mg} / \mathrm{mL}$ crosslinker concentrations. These results suggested that the range of crosslinker concentration from 0 to 2.5 $\mathrm{mg} / \mathrm{mL}$ presented the best condition for spheroid formation and its viability.

\section{Determination of Insulin Secretion}

In order to assess the biological function of these spheroids, insulin secretion capability of the resulting spheroid were measured. Insulin secreted from pancreatic $\beta$-cell spheroid cultured after 7 days with different crosslinker concentrations was determined by ELISA. Fig. (3) shows the amount of the insulin secretion per cell (pg/cell). In serum free condition, the amount of the insulin secretion increased at any crosslinker concentration. Insulin secretion capability was 5.1, 4.5 and 1.9 times greater when using $0.25,2.5$ and $25 \mathrm{mg} / \mathrm{mL}$ crosslinker, respectively. However, the secretion level became low when the resulting spheroids were cultured without serum. On the other hand, in serum-containing medium, insulin secretion from spheroid prepared at the crosslinker concentration of 2.5 and $25 \mathrm{mg} / \mathrm{mL}$ was from 1.8 to 2.1-fold higher than that from cells without crosslinker. The level of insulin secretion from individual cells of sphe- 
FBS (-)
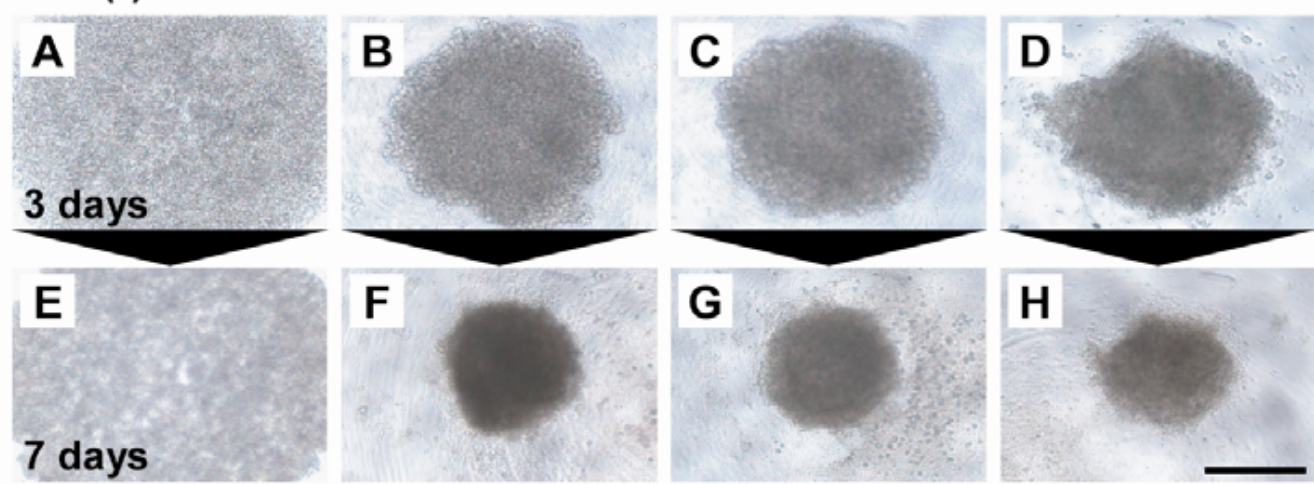

$0 \mathrm{mg} / \mathrm{mL}$

$0.25 \mathrm{mg} / \mathrm{mL}$

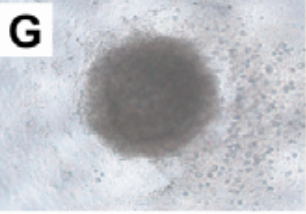

$2.5 \mathrm{mg} / \mathrm{mL}$

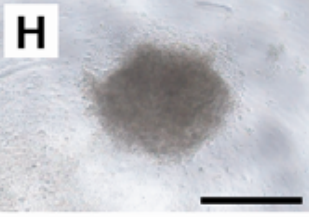

$25 \mathrm{mg} / \mathrm{mL}$

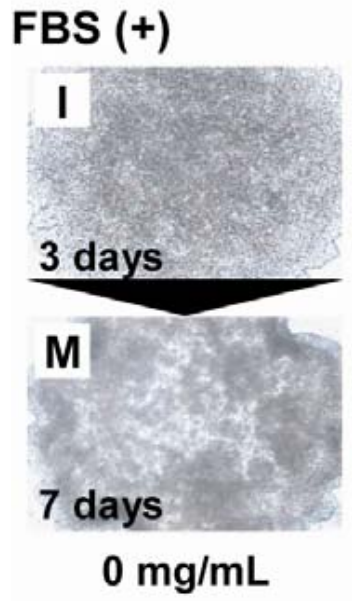

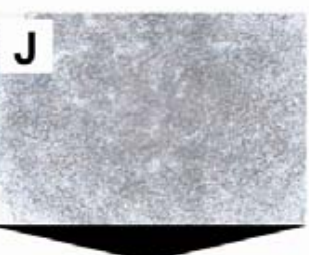

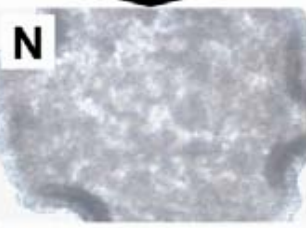

$0.25 \mathrm{mg} / \mathrm{mL}$
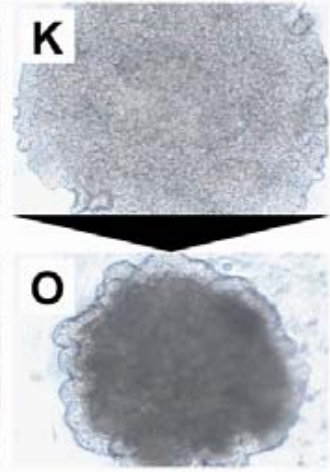

$2.5 \mathrm{mg} / \mathrm{mL}$

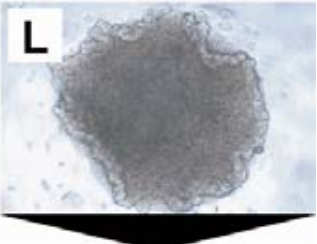

P

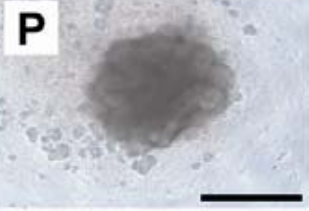

$25 \mathrm{mg} / \mathrm{mL}$

Fig. (1). Microscopic observation on spheroid formation of pancreatic $\beta$-cell (RIN). Photographs of cells cultured at seeding density of $1 \times 10^{5}$ cells/well in serum-free medium for 3 days (A-D) and 7 days $(\mathrm{E}-\mathrm{H})$, and in serum-containing medium for 3 days (I-L) and 7 days (M-P) with crosslinker concentrations of $0 \mathrm{mg} / \mathrm{mL}$ (A, E, I, M), $0.25 \mathrm{mg} / \mathrm{mL}(\mathrm{B}, \mathrm{F}, \mathrm{J}, \mathrm{N}), 2.5 \mathrm{mg} / \mathrm{mL}(\mathrm{C}, \mathrm{G}, \mathrm{K}, \mathrm{O}) \mathrm{and} 25 \mathrm{mg} / \mathrm{mL}(\mathrm{D}, \mathrm{H}, \mathrm{L}, \mathrm{P})$. The scale bar represents $500 \mu \mathrm{m}$.

roid became high when the resulting spheroids were cultured with serum.

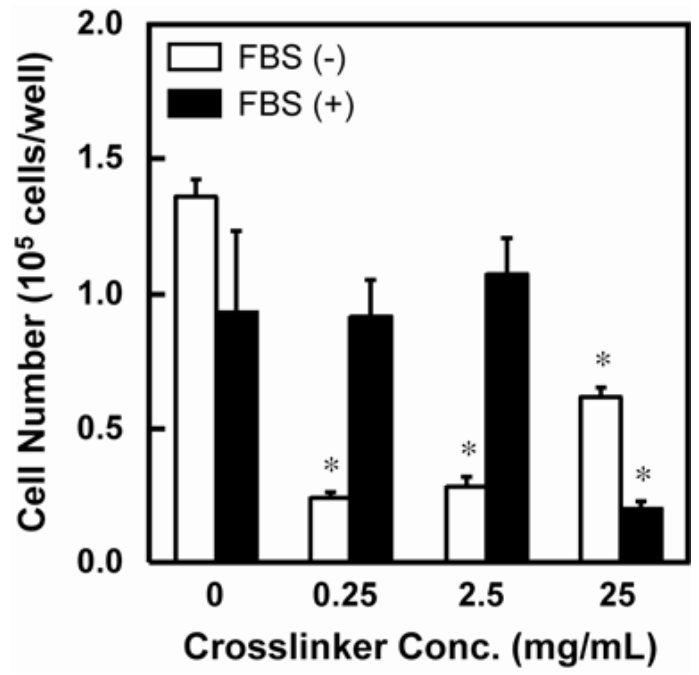

Fig. (2). Determination of cell number in spheroid cultured after 7 days. The white and black bars indicate condition of FBS (-) and $(+)$, respectively. Data are the average \pm S.D. of five samples, with $(*)$ indicating $p<0.01$ versus crosslinker (-).

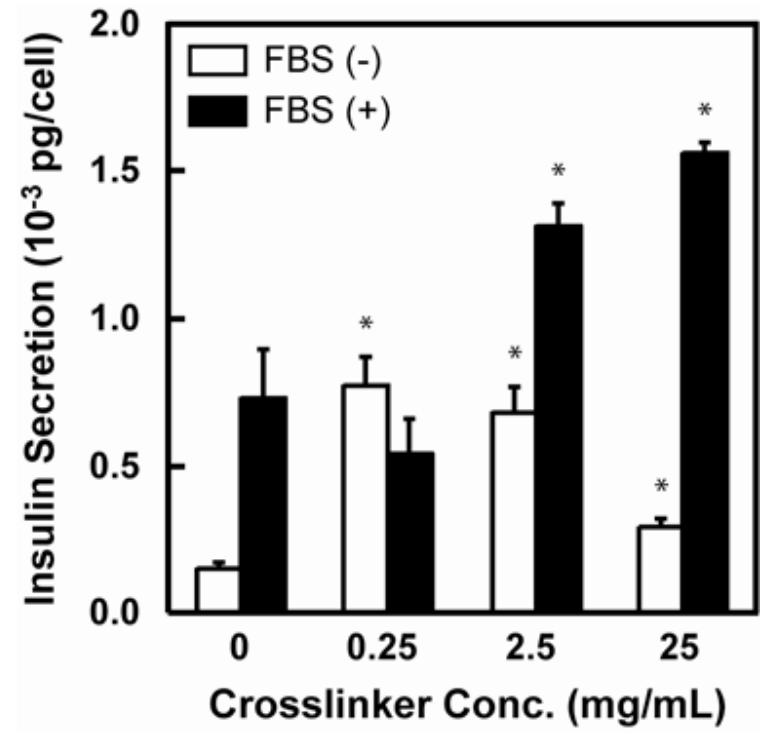

Fig. (3). Insulin secretion in spheroid cultured after 7 days at seeding density of $1 \times 10^{5}$ cells/well and different crosslinker concentrations (Insulin secretion per a cell). The white and black bars indicate condition of FBS (-) and (+), respectively. Data are the average \pm S.D. of five samples, with $\left(^{*}\right)$ indicating $p<0.01$ versus crosslinker $(-)$. 


\section{DISCUSSION}

The prepared PEG-based crosslinker with oleyl groups as hydrophobic group at both the terminal groups was used for the cell culture experiments to evaluate spheroid formation. Cell aggregation was induced when the crosslinker was just added to the cell suspension. As shown in Fig. (1), the size of the resulting spheroid with crosslinker $(2.5 \mathrm{mg} / \mathrm{mL})$ was much smaller than the ones without crosslinker. These results suggested that the cell density was different due to the formation of bridges. In the absence of the crosslinker, the spheroid with large size was due to the loose intercellular junction. While, in the presence of crosslinker, the spheroid with small size was due to the increased crosslinking densities between cells by bridge formations. Also, it was clarified that the size of spheroids decreases with increasing culture time. As the cells are expected to be adjacent to each other by the use of crosslinker, crosslinker plays a temporary role to physically crosslink cells via hydrophobic interaction. After physical crosslink formation, spontaneous cell-cell junction is formed. As the result, spheroid with high crosslinking densities would be formed at high crosslinker concentration. It is supposed that cell-cell junction was formed by the cell adhesion molecules such as E-cadherin in addition to cell-cell junction through the crosslinker after long culture period.

As shown in Fig. (1), serum significantly affected spheroid formation followed by the insulin secretion of the resulting spheroid. When crosslinker was added to cell suspension in the presence of serum, efficiency of crosslinker for spheroid formation became low. Meanwhile, in the absence of serum, spheroid formation was observed even at lower crosslinker concentration $(0.25 \mathrm{mg} / \mathrm{mL})$. There remain some molecules like albumin and lipid in the serum. The decrease in the efficiency of crosslinker for spheroid formation in the presence of serum was due to the suppression of physical crosslinking between cells caused by some lipids or proteins [10]. These results suggested that medium without serum provides favorable condition to promote spheroid formation.

A decrease in the number of cells was observed when the crosslinker was added to the cells in the absence of serum. It is assumed that the component of crosslinker do not show critical cytotoxicity $[9,12]$. This phenomenon was due to the inadequate oxygen and nutrient infiltration followed by necrosis of cells in the center of spheroids [21]. In other words, a decrease in the number of cells is thought to be indirect evidence of the spheroid formation.

The function of resulting spheroid was evaluated by the determination of insulin secretion stimulated by glucose. Actually, effect of crosslinker was observed with respect to the insulin secretion per cell (pg/cell). The increased insulin secretion per cell (pg/cell) was detected at crosslinker concentration of more than $0.25 \mathrm{mg} / \mathrm{mL}$ under serum free condition, and at crosslinker concentration of more than 2.5 $\mathrm{mg} / \mathrm{mL}$ in serum-containing medium. It is supposed that the promoted cell function was due to the enhanced cell-cell and cell-matrix interaction in a spheroid. Even though the insulin secretion from spheroid was enhanced by the addition of crosslinker, cell number in spheroid remained un-changed in serum-containing medium.

\section{CONCLUSION}

Our approach to form spheroids was based on the crosslinking of cell membrane using a polymeric crosslinker via hydrophobic interaction. Using developed polymeric crosslinker, spheroid formation of pancreatic $\beta$-cell line RIN, especially in effect of serum, was investigated. The resulting spheroid size decreased with increasing crosslinker concentration with or without serum and culture time. However, the serum free medium proved to be a favorable condition for promoting spheroid formation, since the serum obstructs hydrophobic unit of the crosslinker. The insulin secretion of the resulting spheroid was enhanced as compared to cells cultured without the use of crosslinker. This polymeric crosslinker was useful for the preparation of cell spheroid with high biological activity.

\section{ACKNOWLEDGEMENTS}

This work was financially supported in part by the Coordination Fund for Promoting Science and Technology from the Ministry of Education, Culture, Sports, Science and Technology of Japan (Development of artificial organs utilizing with nanotechnology and materials science).

\section{REFERENCES}

[1] Langer R, Vacanti JP. Tissue engineering. Science1993; 260: 9206.

[2] Griffith LG, Naughton G. Tissue engineering-current challenges and expanding opportunities. Science 2002; 295: 1009-14.

[3] Drury JL, Mooney DJ. Hydrogels for tissue engineering: scaffold design variables and applications. Biomaterials 2003; 24: 4337-51.

[4] Abbott A. Biology's new dimension. Nature 2003; 424: 870-2.

[5] Service RF. Molecular scaffolding helps raise a crop of neurons. Science 2003; 302: 46-7.

[6] Seo SJ, Kim IY, Choi YJ, et al. Enhanced liver functions of hepatocytes cocultured with NIH $3 \mathrm{~T} 3$ in the alginate/galactosylated chitosan scaffold. Biomaterials 2006; 27: 1487-95.

[7] Kinoshita N, Echigo Y, Shinohara S, et al. Regulation of cell proliferation using tissue engineering in MIN6 cells. Cell Transplant 2001; 10: 473-7.

[8] Lucas-Clerc C, Massart C, Campion JP, et al. Long-term culture of human pancreatic islets in an extracellular matrix: morphological and metabolic effects. Mol Cell Endocrinol 1993; 94: 9-20.

[9] Kato K, Umezawa K, Funeriu DP, et al. Immobilized culture of nonadherent cells on an oleyl poly(ethylene glycol) ether-modified surface. Biotechniques 2003; 35: 1014-22.

[10] Kato K, Itoh C, Yasukouchi T, et al. Rapid protein anchoring into the membranes of mammalian cells using oleyl chain and poly(ethylene glycol) derivatives. Biotechnol Prog 2004; 20: 897 904.

[11] Wang T, Leventis R, Silvius JR. Artificially lipid-anchored proteins can elicit clustering-induced intracellular signaling events in Jurkat T-lymphocytes. independent of lipid Raft association. J Biol Chem 2005; 24: 22839-46.

[12] Miura S, Teramura Y, Iwata H. Encapsulation of islets with ultrathin polyion complex membrane through poly(ethylene glycol)phospholipids anchored to cell membrane. Biomaterials 2006; 27 : 5828-35.

[13] Meier W, Hotz J, Günther-Ausborn S. Vesicle and cell networks: interconnecting cells by synthetic polymers. Langmuir 1996; 12 : 5028-32.

[14] Boonyarattanakalin S, Athavankar S, Sun Q, et al. Synthesis of an artificial cell surface receptor that enables oligohistidine affinity tags to function as metal-dependent cell-penetrating peptides. J Am Chem Soc 2006; 128: 386-7.

[15] Mart RJ, Liem KP, Wang X, et al. The effect of receptor clustering on vesicle-vesicle adhesion. J Am Chem Soc 2006; 128: 14462-3.

[16] Menger FM, Zhang H. Self-adhesion among phospholipid vesicles. J Am Chem Soc 2006; 128: 1414-5. 
[17] Yoshimoto N, Yoshimoto M, Yasuhara K, et al. Evaluation of temperature and guanidine hydrochloride-induced protein-liposome interactions by using immobilized liposome chromatography. Biochem Eng J 2006; 29: 174-81.

[18] Thongborisute J, Takeuchi H, Yamamoto H, et al. Properties of liposomes coated with hydrophobically modified chitosan in oral liposomal drug delivery. Pharmazie 2006; 61: 106-11.

Received: December 17, 2007

Accepted: December 17, 2007
[19] Ito M, Tateishi T, Taguchi T. Synthesis and evaluation of PEG derivatives for crosslinking cells. Macromol Symp 2007; 249-250: 159-161.

[20] Kim Y, Sah RLY, Doong JH, et al. Fluorometric assay of DNA in cartilage explants using Hoechst 33258. Anal Biochem 1988; 174: 168-76.

[21] Sutherland RM, Sordat B, Bamat J, et al. Oxygenation and differentiation in multicellular spheroids of human colon carcinoma. Cancer Res 1986; 46: 5320-9. 